\title{
The EfFect of Action Potential SiMUlation THERAPY ON BLOOD FlOW
}

\begin{abstract}
Action potential simulation therapy (APS) is mostly used for the relief of pain in a variety of conditions. However, the APS user's guide (Lubbe \& Van Zyl, 1997) also lays claim to an effect of increased blood flow which has not yet been supported by published scientific research. The above study was carried out to determine whether APS has an effect on the blood supply of the area under treatment. Ten voluntary,
\end{abstract}

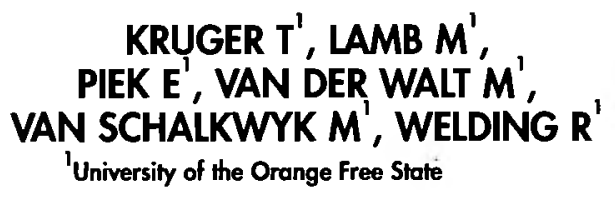

KRUGER T', LAMB $M^{\prime}$, PIEK E', VAN DER WALT $M^{\prime}$ ', VAN SCHALKWYK $M^{1}$, WELDING $R^{\prime}$

'University of the Orange Free State healthy men were used as experimental subjects. Factors that could affect their blood flow and that served as exclusion criteria, could not be found. Blood flow was normalised by a resting period of 30 minutes before application. A radioactive substance ( $99 \mathrm{~m}$ Tc-sestamibi) was injected intravenously. The blood flow baseline was determined by means of tomographic studies on a gamma camera. A standard application of APS was administered for 16 minutes at $2 \mathrm{~mA}$. Blood flow was determined immediately after this. Two further measurements with an interval of 15 minutes were taken thereafter. Although associated non-parametric confidence intervals for the median difference in blood flow from baseline was not statistically or clinically significant, the blood flow of 8 experimental subjects increased after 41 minutes of administration, while it decreased in only 2 experimental subjects. After the ensuing 15 minutes (thus at 56 minutes) the blood flow of 6 experimental subjects increased and that of 4 decreased. It can therefore not be stated with certainty that APS increases blood flow in the area under treatment. 